\title{
A high-precision digital astrogeodetic traverse in an area of steep gravity gradients close to the coast of Perth, Western Australia
}

\author{
P. Schack ${ }^{1 *}$, C. Hirt ${ }^{1}$, M. Hauk ${ }^{1}$, W.E. Featherstone ${ }^{2}$, T.J. Lyon ${ }^{2}$ and S. Guillaume ${ }^{3}$ \\ ${ }^{1}$ Institute of Astronomical and Physical Geodesy, Technical University of Munich, Arcisstrasse 21, 80333 Munich, Germany \\ ${ }^{2}$ Department of Spatial Sciences and The Institute for Geoscience Research, Curtin University of Technology, GPO Box U1987, \\ Perth WA 6845, Australia \\ ${ }^{3}$ Institute of Geodesy and Photogrammetry, Swiss Federal Institute of Technology Zurich, Robert-Gnehm-Weg 15, 8093 Zurich, \\ Switzerland
}

\begin{abstract}
We present results from a new vertical deflection (VD) traverse observed in Perth, Western Australia, which is the first of its kind in the Southern Hemisphere. A digital astrogeodetic QDaedalus instrument was deployed to measure VDs with $\sim 0.2$ " precision at 39 benchmarks with a $\sim 1 \mathrm{~km}$ spacing. For the conversion of VDs to quasigeoid height differences, the method of astronomical-topographical levelling was applied, based on topographic information from the Shuttle Radar Topography Mission (SRTM). The astronomical quasigeoid heights are in \pm 20 $30 \mathrm{~mm}$ (RMS) agreement with three independent gravimetric quasigeoid models, and the astrogeodetic VDs agree to $\pm 0.2-0.3$ " (north-south) and \pm 0.5 -0.9" (east-west) RMS. Tilt-like biases of $\sim 10 \mathrm{~mm}$ over $\sim 10$ $\mathrm{km}$ are present for all quasigeoid models within $\sim 20$ $\mathrm{km}$ of the coastline, suggesting inconsistencies in the coastal zone gravity data. The VD campaign in Perth was designed as a low-cost effort, possibly allowing replication in other Southern Hemisphere countries (e.g., Asia, Africa, South America and Antarctica), where VD data are particularly scarce.
\end{abstract}

Keywords: Vertical deflections, astronomical levelling, geoid validation, coastal zone geodesy

\section{Introduction}

Vertical deflections (VDs) are the angular difference between the direction of the plumbline and some reference direction (e.g., Jekeli 1999). The direction of the plumbline (true vertical) is defined through the gravity vector. In Molodensky's definition of the VD, the normal plumbline (at the telluroid) serves as the reference direction. In Helmert's definition, VDs are defined as angle between the direction of the gravity vector at the Earth's surface and the ellipsoidal surface normal through the same point. Each definition differs by the curvature of the normal plumbline (e.g., Torge and Müller 2012, p 107). VDs in Helmert's definition are directly obtained from astrogeodetic observations (e.g., Hirt et al. 2010a).

Astrogeodetic VDs come from precisely timed observations to the fixed stars, where the resulting astronomic coordinates are compared with co-located geo- detic coordinates to provide the north-south $(\xi)$ and east-west $(\eta)$ VD components. Historically, photographic and geodetic surveying techniques were used, but over the past 15 years they have been replaced by CCD (charged coupled device) cameras and GPS (Global Positioning System) in fully digital systems (e.g., Hirt et al. 2010a; Guillaume et al. 2012).

Astrogeodetic VDs have played several important roles in geodesy and geophysics. Astronomical levelling was the only means for geoid determination prior to gravimetric methods, though combined astrogravimetric methods have also been used (e.g., Fryer 1972, Marti 1997). VDs are needed for the reduction of geodetic surveying measurements to the ellipsoid (e.g., Featherstone and Rüeger 2000), have been used to assess high-resolution global gravity field models (e.g., Jekeli 1999), and can be applied to fit gravimetric geoid models (Featherstone and Lichti 2009). Astrogeodetic VDs also helped to confirm the principle of isostasy (e.g., Watts 2001, Chap. 1) and have been applied to geophysical studies of intracrustal massdensity anomalies (Bürki 1989).

With the advent of the digital zenith camera, astrogeodetic VDs have been observed and used to compute quasi/geoid profiles (e.g., Hirt et al. 2007; Hirt and Seeber 2007; Hirt et al. 2008; Hirt and Flury 2008; Voigt et al. 2009; Voigt 2013; Smith et al. 2013; Guillaume 2015; Wang et al. 2017), but only for Northern Hemisphere countries. In the aforementioned works, sub-mm, $\mathrm{mm}$ and $\mathrm{cm}$ precision was achieved for quasi/geoid height differences depending on the traverse length, VD station spacing and instrument accuracy. These new VD datasets were not only used for independent quasi/geoid validation based on astronomical levelling, but also error analysis of GNSS heighting (Hirt et al. 2011), and in the assessment of the high-frequency constituents of geopotential models (e.g., Hirt et al. 2010b; Voigt 2013; Voigt and Denker 2013). Historical VD traverses have been conducted in Australia for astrogeodetic geoid determination (e.g., Fischer et al. 1968; Fryer 1972), but were analogue, and of lower precision than modern VD measurements. 

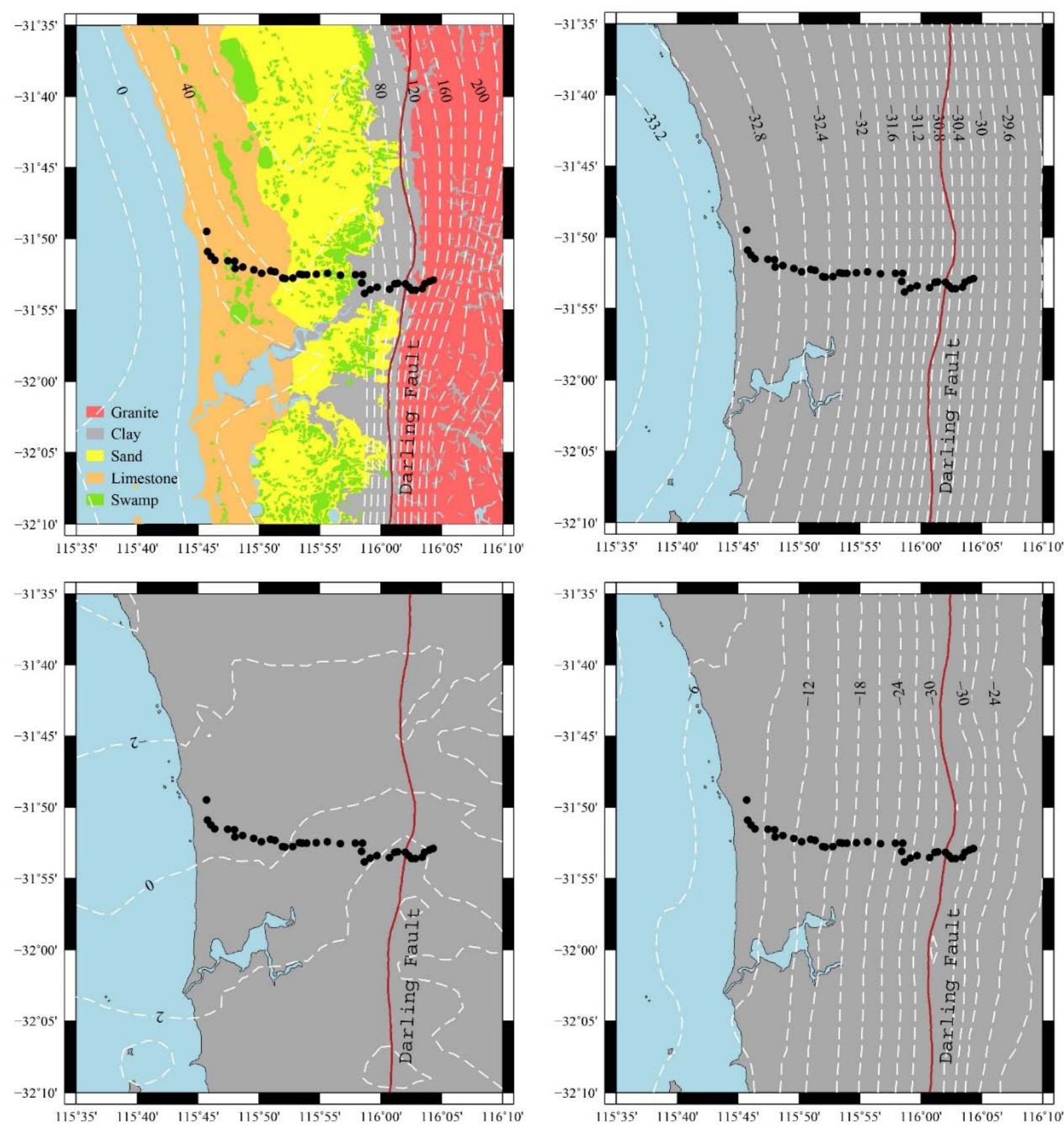

Fig. 1. Study area in Perth, Western Australia. (a) Surface geology digitised from Davidson (1995) with elevations contoured from SRTM, (b) AGQG2017 quasigeoid heights in metres, showing the steep east-west gradient ( 70 ppm) due to the juxtaposition of the Perth Basin and Yilgarn Craton along the north-south Darling Fault, (c) AGQG2017 north-south VD in arc-seconds, (d), AGQG2017 east-west VD in arc-seconds. The astrogeodetic traverse is shown by black circles.

The objective of this study is to introduce a new VD dataset acquired with digital instrumentation in the Southern Hemisphere, and to exemplify the use of this dataset for validation of existing gravity field models. The digital QDaedalus instrument (Guillaume et al. 2012) was deployed in Perth, Western Australia in February 2017 to measure 39 astrogeodetic VDs along a $\sim 38 \mathrm{~km}$ traverse (Fig. 1). This study area was deliberately chosen because 1) it hosts one of the steepest geoid gradients in the world due to the juxtaposition of the low bulk density Perth Basin and high bulk density Yilgarn Craton (topographic bulk density contrasts reach $480 \mathrm{kgm}^{-3}$ (Middleton et al. 1993)) that are separated by the nearvertical $15 \mathrm{~km}$-deep Darling Fault, and 2) its close proximity to the ocean where problems associated 
with coastal marine gravity quality and the sea-land transition can affect the quality of gravimetric quasigeoid models. The acquired VDs are exemplarily used to assess global and regional gravimetric quasigeoid models in this "gravimetrically challenging" region.

\section{Datasets}

\subsection{Astrogeodetic VDs and auxiliary measurements}

The measurement process and data processing of the QDaedalus system are explained in Hauk et al. (2017) and Guillaume et al. (2012), so not replicated here. From 15 February to 01 March 2017, weather conditions permitted QDaedalus observations of astronomic coordinates on 13 nights at 39 different benchmarks (BMs) along an east-west traverse (up to four BMs per night). The location of the astrogeodetic traverse is shown in Fig. 1 and together with surface geology (Davidson 1995) and AGQG2017 (Featherstone et al. 2017) quasigeoid heights and AGQG2017 VDs. For the astronomical orientation of the system, stars of the Crux, Triangulum Australe or Carina constellations were targeted, depending on local time and sky visibility. A set of three consecutive observation sessions were performed at or near each BM, each taking 15 minutes and resulting in $\sim 300$ angular measurements. The observations from all sessions were averaged to reduce random error sources (e.g., scintillation).

For internal validation and evaluation of the results, observations were repeated at six BMs, on different nights. The quality assessment yielded standard deviations of \pm 0.17 " for the north-south VD $(\xi)$ and \pm 0.23 " for the east-west VD $(\eta)$. These numbers do not contradict the standard deviations of \pm 0.15 ” to \pm 0.20 ", which were determined based on repeat and comparison measurements in Germany prior to the campaign (Hauk et al. 2017).

Geodetic coordinates (Geocentric Datum of Australia 1994)) for the majority of BMs were available from the State's register of surveying control marks, the majority of these having been previously coordinated by relative carrier-phase GNSS surveys with a mean horizontal precision of $\pm 7 \mathrm{~mm}$ at one-sigma. At BMs with less accurate geodetic coordinates (i.e., BMs with horizontal coordinates scaled from maps), or when the QDaedalus system had to be deployed eccentrically for better sky visibility, co-located short-occupation static GNSS baselines were observed simultaneously with the astrogeodetic observations relative to two International GNSS Station (IGS) control stations (PERT and CUT0) in "faststatic" mode, with fixed integer ambiguity solutions, and a mean horizontal precision of $\pm 56 \mathrm{~mm}$ at onesigma. These STDs translate to an angular uncer- tainty of 0.0002 " and 0.002 " in the geodetic coordinates.

Surface gravity measurements along the profile, with a mean precision of $\pm 0.01 \mathrm{mGal}$ at one-sigma, provide auxiliary data for the astronomical levelling (Section 3). They were collected during a relative gravity survey conducted in December 2015 using a Scintrex CG5 digital gravimeter, connected to a base station of the Australian Absolute Gravity Datum 2007, but have not been used in any of the gravimetric quasigeoid models tested here.

\subsection{Gravity field models for comparisons}

We use GGMplus (Hirt et al. 2013) as model for comparisons with (1) measured VDs, (2) modelled quasigeoid heights, and (3) for test computations in the remove-compute-restore (RCR) combination with measured VDs. GGMplus is a composite gravity model that relies on satellite (GRACE, GOCE) and EGM2008 (Pavlis et al, 2012, 2013) terrestrial gravity information at spatial scales of $\sim 10,000 \mathrm{~km}$ to $\sim 10$ $\mathrm{km}$ and topography-implied gravity values at spatial scales of $\sim 10 \mathrm{~km}$ to $\sim 250 \mathrm{~m}$. VDs (in Helmert's definition) and quasigeoid heights from GGMplus are available

http://ddfe.curtin.edu.au/models/GGMplus/.

We include AGQG2017 (Featherstone et al. 2017), a regional gravimetric quasigeoid model based on EGM2008. It includes location-specific error estimates propagated from EGM2008 and the local gravity and terrain data. Over the study area, the uncertainty is $\sim 90 \mathrm{~mm}$. We also use the AGQG2009 regional gravimetric quasigeoid model (Featherstone et al. 2011), the predecessor to AGQG2017. Opposed to GGMplus, the two AGQG models are based on gravimetric information (marine and terrestrial) also at spatial scales less than $\sim 10 \mathrm{~km}$.

We emphasise the different character of the astronomical and gravimetric solutions. While the astronomical solution is unbiased from a conceptual point of view, gravimetric solutions may suffer from biases (here via low-accuracy coastal marine gravity, cf. Sections 3 and 4) that propagate via the geodetic convolution integral (modified Stokes integration in case of the Australian models) into the quasigeoid solutions. The astronomical solution provides quasigeoid height differences along a profile (1D), while the gravimetric solution delivers a grid of quasigeoid heights (2D), cf. Torge and Müller (2012).

\section{Astronomical levelling \\ 3.1 Summarised theory}

Our astrogeodetic VDs follow the Helmert definition, i.e., the astronomical coordinates (astronomical lati- 
tude $\Phi$, longitude $\Lambda$ ) define the direction of the physical plumbline and the geocentric geodetic coordinates (geodetic latitude $\varphi$, longitude $\lambda$ ) the direction of the ellipsoidal normal at the observation point. Astrogeodetic VDs were obtained using (e.g., Voigt 2013)

$$
\begin{gathered}
\xi=\sin \Phi \cos \varphi-\cos \Phi \sin \varphi \cos (\Lambda-\lambda), \\
\eta=\sin (\Lambda-\lambda) \cos \Phi
\end{gathered}
$$

that avoid approximation errors (few 0.01" in mountainous terrain, but smaller in flat terrain) associated with the often used first-order Taylor series

$$
\begin{gathered}
\xi=\Phi-\varphi, \\
\eta=(\Lambda-\lambda) \cos \varphi .
\end{gathered}
$$

Following the theory of astronomical levelling (Helmert 1880/1884), VDs observed at the Earth's surface are numerically integrated along a path to obtain quasigeoid height differences (Torge and Müller 2012, p. 298)

$$
\Delta \zeta_{A B}=-\int_{A}^{B} \varepsilon d s-N C
$$

where $A$ and $B$ denote the endpoints of the path, $\varepsilon=\xi \cos \alpha+\eta \sin \alpha$ is the VD component in geodetic azimuth $\alpha, d s$ is the geodesic distance between adjacent VD stations, and $N C$ is the normal correction, used to obtain quasigeoid height differences (Torge and Müller, 2012, p. 254)

$$
N C=\int_{A}^{B} \frac{g-\gamma}{\gamma} d n+\frac{\bar{\gamma}_{A}-\gamma}{\gamma} H_{A}-\frac{\bar{\gamma}_{B}-\gamma}{\gamma} H_{B}
$$

which depends on surface gravity values $g$, height differences $d n$ between adjacent stations, mean normal gravity values $\bar{\gamma}_{A}, \bar{\gamma}_{B}$ along the plumblines of the endpoints $A$ and $B$, and an arbitrary constant normal gravity value $\gamma=\gamma_{0}^{45}$ ( $\gamma_{0}^{45}$ is the normal gravity at $45^{\circ}$ geodetic latitude). GRS80 (Moritz 2000) has been used throughout. The combined and discretised form of Eqs. (3) and (4) is

$$
\begin{gathered}
\Delta \zeta_{A B} \approx-\sum_{i=1}^{n-1}\left(\frac{\left(\xi_{i}+\xi_{i+1}\right)}{2} \cos \alpha\right. \\
\left.+\frac{\left(\eta_{i}+\eta_{i+1}\right)}{2} \sin \alpha\right) d s_{i, i+1}- \\
\sum_{i=1}^{n-1}\left(\frac{0.5\left(g_{i}+g_{i+1}\right)-\gamma}{\gamma}\right) d n_{i, i+1}+\frac{\bar{\gamma}_{A}-\gamma}{\gamma} H_{A} \\
-\frac{\bar{\gamma}_{B}-\gamma}{\gamma} H_{B}
\end{gathered}
$$

where indices $i$ and $i+1$ denote adjoining stations with VDs, gravity values and height differences. The $d n$ and $g$ values are needed for the numerical evaluation of the $N C . H_{A}$ and $H_{B}$ are normal heights from the levelling traverse or can be approximated through a digital elevation model (DEM).

\subsection{Practical evaluation}

The evaluation of Eq. (3) requires densely spaced VDs such that the deflection data of adjacent stations can be interpolated linearly. We applied the method of astronomical-topographical levelling (Bosch and Wolf 1974; Hirt and Flury 2008) using a RCR technique.

The method of astronomical-topographical levelling, as described e.g. by Hirt and Flury (2008), uses topographic reductions of VDs for the interpolation between astrogeodetic stations. Different to the original description of Hirt and Flury (2008), we interpolate observed VDs with modelled VDs from

(1) residual terrain model (RTM, Forsberg 1984) data instead of topographic forward modelling with a full-scale topography model truncated beyond a $200 \mathrm{~km}$ integration radius. Our RTM is based on a 1 arc-sec SRTM model with a degree-2160 spherical harmonic DEM reference surface removed.

(2) GGMplus (Hirt et al. 2013) that merges GRACE, GOCE and EGM2008 gravity information at long- and medium-wavelengths (harmonic degrees 2 to 2190) with short-wavelength gravity information obtained from a RTM based on 7.2 arc-sec SRTM topography.

The RTM forward modelling was done with the Fortran software "TC" (Forsberg 1984), along with a $\sim 200 \mathrm{~km}$ integration cap radius and the residual SRTM topography. The height differences $d n$ were interpolated from the SRTM model and the gravity values $g$ obtained through application of the RCR technique with observed gravity and SRTMpredicted gravity. In this topographically low-lying region (max $\sim 200 \mathrm{~m}$; Fig. 1a), the $N C$ term (Eq. 2) is less than $5 \mathrm{~mm}$.

Figure 2 shows the observed VDs along the Perth traverse, and their RCR-based combination with RTM-data and with GGMplus. The $\xi$-component shows a dominant linear behaviour and reaches values from -1.4" in the west to +3.1" in the east (Table 1 and Fig. 2). Short-scale variations remain less than 1 ". The $\eta$-component exhibits a large decrease from 7.0" to -32.5” (Table 1 and Fig. 2) from the west up to the Darling Fault (32-33 km along the profile), followed by a sharp peak and slowly increasing VD values eastward of the Fault. The deflections for the two variants (GGMplus and forward modelling based on $30 \mathrm{~m}$ SRTM) are very similar, with RMS differences of \pm 0.07 " for $\xi$ and \pm 0.09 " for $\eta$. The differences primarily reflect high-frequency signals associated with the higher spatial resolution of the 1-arcsec resolution SRTM dataset. 

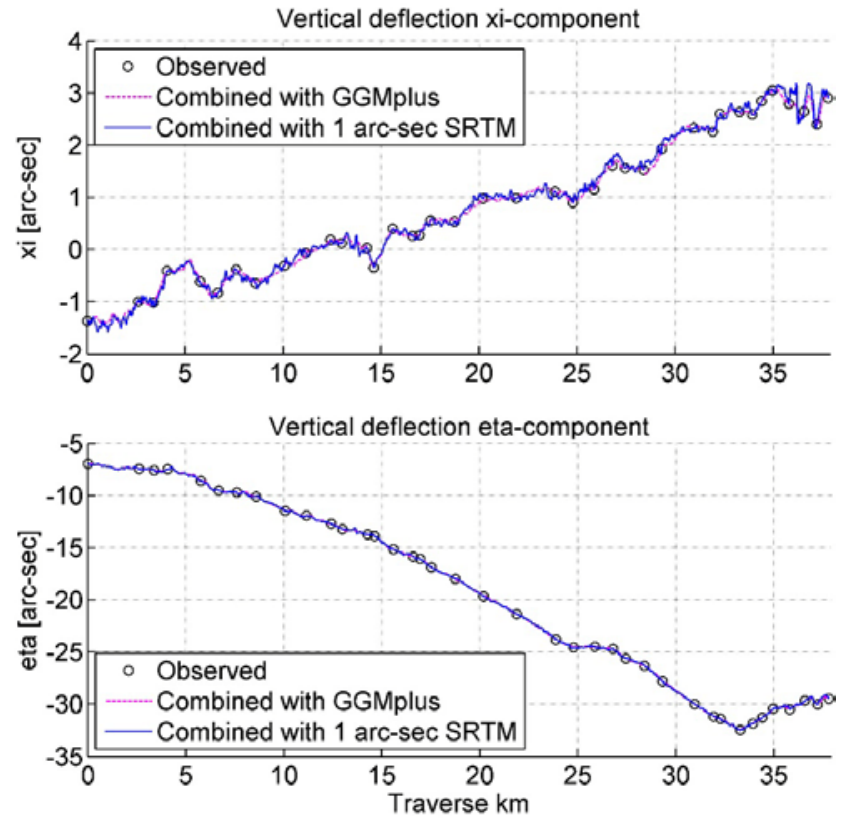

Fig. 2. VDs along the Perth traverse. Units in arc-seconds. Top: north-south component $\xi$, Bottom: east-west component $\eta$. Astronomically measured VDs (black circles), GGMplus RCRcombination (magenta) and SRTM V3 RCR-combination (blue). The large east-west VDs reflect the steep quasigeoid gradient in the Perth region due to the Darling Fault.

Table 1. Descriptive statistics of the VDs along the Perth traverse - observations, GGMplus, AGQG2009 and AGQG2017, and differences between the observations and models. Units in arcseconds.

\begin{tabular}{|c|c|c|c|c|c|}
\hline & Source & Min & Max & Mean & RMS \\
\hline \multirow{7}{*}{$\xi$} & Observed & -1.37 & 3.05 & 0.93 & 1.61 \\
\hline & GGMplus & -0.98 & 3.44 & 0.96 & 1.62 \\
\hline & AGQG2009 & -1.37 & 2.68 & 0.91 & 1.57 \\
\hline & AGQG2017 & -1.15 & 2.51 & 0.78 & 1.45 \\
\hline & $\begin{array}{l}\text { Observed- } \\
\text { GGMplus }\end{array}$ & -0.63 & 0.40 & -0.04 & 0.30 \\
\hline & $\begin{array}{l}\text { Observed- } \\
\text { AGQG2009 }\end{array}$ & -0.41 & 0.79 & 0.02 & 0.23 \\
\hline & $\begin{array}{l}\text { Observed- } \\
\text { AGQG2017 }\end{array}$ & -0.28 & 1.10 & 0.15 & 0.31 \\
\hline \multirow{7}{*}{$\eta$} & Observed & -32.47 & -7.00 & -20.08 & 21.88 \\
\hline & GGMplus & -30.87 & -8.08 & -20.16 & 21.82 \\
\hline & AGQG2009 & -30.64 & -8.10 & -20.04 & 21.62 \\
\hline & AGQG2017 & -31.88 & -7.79 & -20.30 & 21.99 \\
\hline & $\begin{array}{l}\text { Observed- } \\
\text { GGMplus }\end{array}$ & -2.46 & 1.39 & 0.08 & 0.89 \\
\hline & $\begin{array}{l}\text { Observed- } \\
\text { AGQG2009 }\end{array}$ & -1.89 & 1.22 & -0.04 & 0.71 \\
\hline & $\begin{array}{l}\text { Observed- } \\
\text { AGQG2017 }\end{array}$ & -1.30 & 1.21 & 0.22 & 0.56 \\
\hline
\end{tabular}

\subsection{Precision and accuracy estimation}

The standard deviation of the VDs is at the level of $\pm 0.15-0.20$ " (Hauk et al. 2017), cf. Sect. 2. This random error in the VD data translates into a $1 \mathrm{~mm}$ error in quasigeoid heights over $1 \mathrm{~km}$, and accumulates (with the square root of the number of stations (e.g., Hirt and Flury 2008) to $\sim \pm 4-6 \mathrm{~mm}$ standard deviation in the quasigeoid height differences (over $38 \mathrm{~km}$ ). From Hirt and Flury (2008, Table 9), the impact of the signal omission error due to the $\sim 1 \mathrm{~km}$ spacing is estimated to reach the $\sim 1 \mathrm{~mm}$ level over the traverse. This simple precision assessment does not take into account errors associated with the topographic VDs used in the interpolation, which are at the mm level. The uncertainty of the $N C$ computation is estimated not to exceed $1 \mathrm{~mm}$. This estimate is based on empirical results from other astronomic surveys in more rugged terrain and over longer traverses (Hirt et al. 2008).

More important than random errors, undetected systematic errors of the observed VDs propagate linearly with the length of the traverse into the quasigeoid heights. For instance, a systematic error of 0.01 " falsifies $\Delta \zeta_{A B}$ by $0.05 \mathrm{~mm}$ (over $1 \mathrm{~km}$ ) and $1.9 \mathrm{~mm}$ (over $38 \mathrm{~km}$ ). Accordingly, a systematic error of 0.05 " would cause a $10 \mathrm{~mm}$ bias in $\Delta \zeta_{A B}$ towards the ends of the traverse. From the comparison against GGMplus (Table 1), possible biases in the VD data can be assumed not to exceed the $~ 0.06$ " level in the east-west direction.

Regarding the source of biases or residual errors in the VD data, some possible effects are as follows. 1) The effect of Earth tides on the direction of the physical plumbline may reach maximum values of 0.01"-0.02” (cf. Jekeli 1999; Voigt et al. 2013). Earth tide corrections were not applied in this study because they remain mostly below $\sim 5-10 \%$ of the observational accuracy. 2) The effect of anomalous atmospheric refraction might cause amplitudes of few 0.05” at time scales of hours (Hirt 2006), but smaller amplitudes at time scales of several days or weeks (e.g., 0.01”, Hirt and Seeber 2008). Explicit modelling of parts of the refraction effects through ray-tracing through $3 \mathrm{D}$ atmospheric weather models is possible in principle (Guillaume 2015, p241 ff), but was envisaged here due to the demanding requirements in terms of temporal and spatial resolution of the atmospheric data that would be required. 3) As far as instrumental systematic effects are concerned, comparisons between VDs from QDaedalus measured at digital zenith camera sites (Hauk et al. 2017) and at a control site of TU Munich before and after the campaign did not give evidence for observational biases (e.g., systematic instrumental errors).

4) Another effect that can cause biases between gravity field observations and models is the underlying reference frames (Kotsakis 2009, Featherstone 1995). In the case of our observed VDs, the underlying reference frame for the geodetic coordinates in GDA94 is ITRF92 (epoch 1994.0). This differs from ITRF2014 by $\sim 2 \mathrm{~m}$ in a north-east direction, which would translate to a systematic $\sim 0.06$ " in each deflection component if it were to be compared to a gravity model with ITRF2014 as the underlying reference 
frame. For satellite-only global gravity models, the reference frame is implicit from the tracking stations. For combined gravity models such as GGMplus, AGQG2009 and AGQG2017, it also depends on the underlying reference frames for the gravity data and terrain data used. For AGQG2009 and AGQG2017, the horizontal coordinates of the gravity and terrain data were GDA94 (ITRF92 epoch 1994.0), so the underlying reference frame of the high-frequency model constituents is compatible with the GDA94 geodetic coordinates used to calculate our astrogeodetic VDs. In the case of GGMplus, the highfrequency constituents depend on SRTM elevation data, which is assumed to refer to WGS84(G873) (Brown et al. 2005). The underlying reference frame is therefore ITRF94 (epoch 1997) and the effect on the VDs is estimated to be below 0.01". However, in all models there is also a dependency on the underlying reference frames of EGM2008, assumed to be GDA94 for Australian gravity data and ITRF94 for SRTM. In summary, the upper limit of the reference frame inconsistency can be constrained to $~ 0.06$ ”, but is likely to be less because the epochs of the input datasets of the gravity models used in this study are closer to 1994.0 than 2014.0, or identical with 1994.0.

Based on all stochastic information available, we consider a standard deviation of $\pm 10 \mathrm{~mm}$ to $\pm 15 \mathrm{~mm}$ for $\Delta \zeta_{A B}$ over the $38 \mathrm{~km}$ traverse length to be realistic.

\section{Model comparison results \\ 4.1 Vertical deflection comparisons}

Figure 3 shows the observed VDs together with AGQG2009, AGQG2017 and GGMplus-only, which are independent of the observed VDs and vice versa. Figure 4 shows the differences between the astrogeodetic VDs and those from the models; for the descriptive statistics of the VDs and their differences, see Table 1. Astrogeodetic VDs can be directly compared with GGMplus VDs, given both are in Helmert definition (Hirt et al. 2013, supplementary materials). For the comparison with VDs from the AGQG models, the model VDs were derived from horizontal quasigeoid gradients so transformed to the Helmert definition $(\xi, \eta)^{H}$ as follows.

In the first step, the gridded quasigeoid values were used to compute VDs in Molodensky definition $(\xi, \eta)_{Q G}^{M}$ (cf. Heiskanen and Moritz 1967, p 313, Voigt 2013)

$$
\begin{gathered}
\xi_{Q G}^{M}=-\frac{1}{M+h} \frac{\partial \zeta}{\partial \varphi}-\Delta \xi \\
\eta_{Q G}^{M}=-\frac{1}{(N+h) \cos \varphi} \frac{\partial \zeta}{\partial \lambda}-\Delta \eta
\end{gathered}
$$

where $M$ is the meridian curvature radius, $N$ the prime vertical curvature radius (see Torge and Müller 2012, p95), $h$ the ellipsoidal height, and $\Delta \xi, \Delta \eta$ are terrain slope correction terms

$$
\begin{gathered}
\Delta \xi=\frac{\Delta g}{\gamma} \frac{1}{M+h} \frac{\partial h}{\partial \varphi} \\
\Delta \eta=\frac{\Delta g}{\gamma} \frac{1}{(N+h) \cos \varphi} \frac{\partial h}{\partial \lambda}
\end{gathered}
$$

that take into account that the Earth's topographic surface is not an equipotential surface. The terrain slope correction terms depend on the gravity anomaly $\Delta g$, normal gravity $\gamma$ and the terrain slopes in north-south $(M+h)^{-1} \partial h / \partial \varphi$ and east-west direction $((N+h) \cos \varphi)^{-1} \partial h / \partial \lambda$, respectively. In the second step, VDs are transformed from Molodensky $(\xi, \eta)_{Q G}^{M}$ to Helmert $(\xi, \eta)_{Q G}^{H}$ definition via

$$
\begin{gathered}
\xi^{H}=\xi^{M}+0.17^{\prime \prime} H \sin 2 \varphi \\
\eta^{H}=\eta^{M}
\end{gathered}
$$

where $H$ is the normal height in km (Jekeli 1999) and the difference in $\xi$ is due to the curvature of the normal plumbline. VDs from Eq. (8) can then be compared with the (Helmert) astrogeodetic VDs.
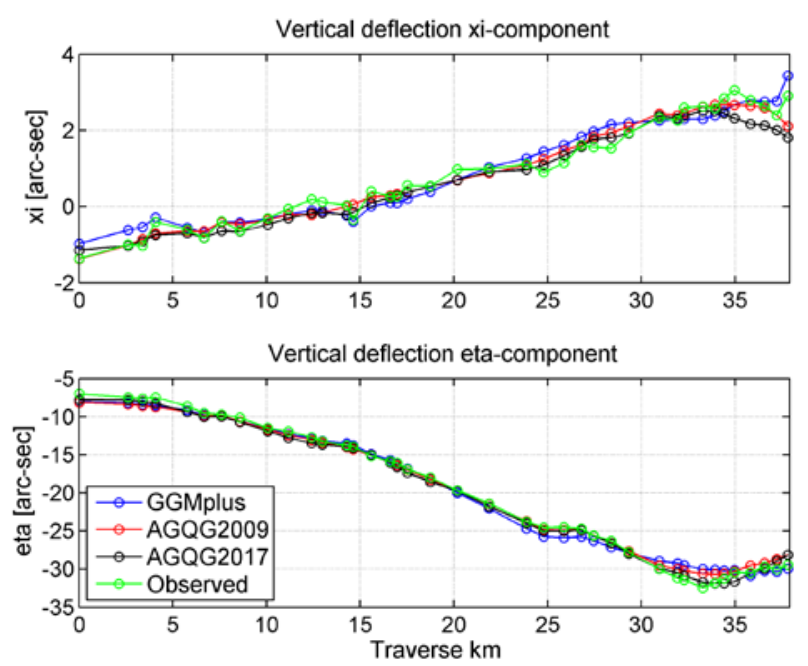

Fig. 3. VDs along the Perth traverse. Units in arc-seconds. Top: north-south component $\xi$, Bottom: east-west component $\eta$. GGMplus-predicted deflections (blue), AGQG2009-predicted deflections (red), AGQG2017-predicted deflections (black), astronomically observed VDs (green).

According to Voigt (2013, p 106), the terrain slope terms [Eq. (7)] are a "central problem" because the "limited accuracy of the terrain slopes, particularly in rough topography, leads to systematic deviations" in their computation. We attempted to calculate the terrain slope correction terms with DEMs of different resolution, and gravity anomalies from high-resolution global models. However, because of the large amplitudes of gravity anomalies over most of the traverse ( $100 \mathrm{mGal})$, errors of a few metres in the DEM were found to translate into several 0.1" 
errors in the $\Delta \xi, \Delta \eta$ correction terms, deteriorating the quality of the VDs in Eq. (7) along the traverse.
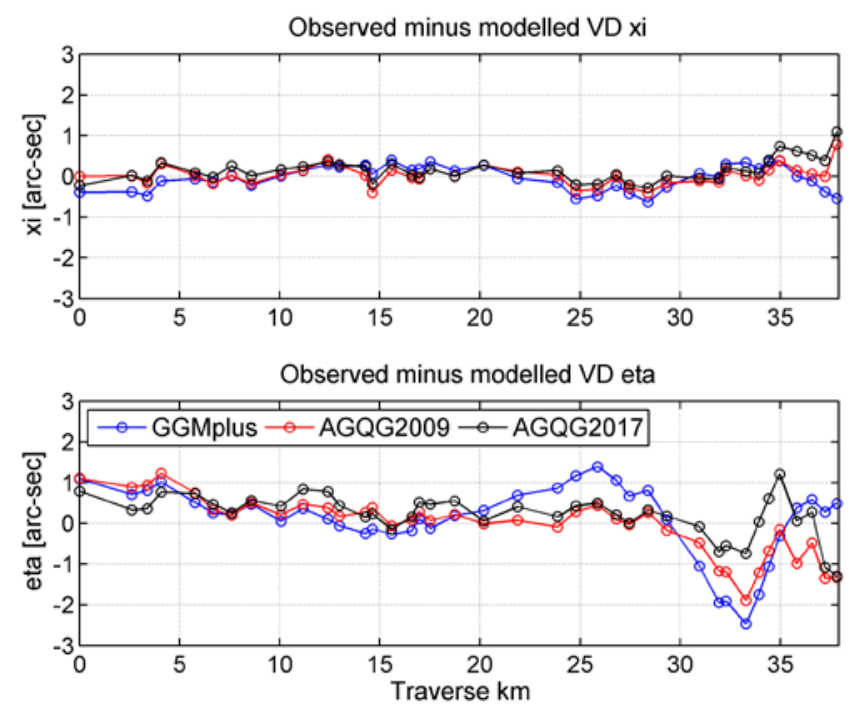

Fig. 4. Differences between observed and modelled VDs. Units in arc-seconds. Top: $\xi$-component, Bottom: $\eta$-component.

A principal problem appears to be the spectral inconsistency between quasigeoid grids (e.g., $1 \mathrm{~min}$ resolution) and DEMs to consistently model the difference between the level surfaces and terrain surface. Therefore, we decided not to apply the slope correction terms in this study. The encountered difficulties suggest that the accurate prediction of Helmert VDs from quasigeoid models using the formalism of Eqs. (6)-(8) can be problematic where large gravity anomalies "amplify" errors in the terrain slopes. We note that the comparison of quasigeoid height differences from astronomical levelling with gravimetric quasigeoid information (Sect. 4.2) does not require slope correction terms, so avoids such difficulties with their computation.

From Figs. 3 and 4 and Table 1, for all three models, the RMS of the $\xi$ differences is less than \pm 0.3 ", which is close to the observational precision of the QDaedalus instrument (Guillaume et al. 2012; Hauk et al. 2017). There are larger discrepancies at the eastern end of the traverse (toward the right in Fig. 4) that coincides with the location of the Darling Fault, with larger differences exhibited in the $\eta$-component than in $\xi$. These differences exceed 2" and show an RMS ranging from \pm 0.5 ” to \pm 0.9 ”, reflecting the presence of large bulk density anomalies in the eastwest direction (cf. Fig. 1 a). The differences along the first $30 \mathrm{~km}$ are predominantly positive, at the level of +0.1 " to +0.2 ". This may indicate a bias, either in the observed VDs or in the VDs calculated from the three quasigeoid models (Sect. 4.3). Since no evidence for a bias was found in Hauk et al. (2017, Fig. 4), assessing the quality of QDaedalus measurements, it is more likely to be associated with the GGMplus, AGQG2009 and AGQG2017 models of the very steep east-west quasigeoid gradient in Perth, as well as the lower precision of the marine gravity data.

The RMS values of the differences never exceed \pm 1 ” for any of the three models (Table 1 ), which is commensurate with investigations using astrogeodetic VDs in Northern Hemisphere countries (e.g., Hirt et al. 2010b; Smith et al. 2013; Wang et al. 2017). As such, our study corroborates the ability of global or regional models to predict VDs at the 1" precision level or better over topographically flat areas. Furthermore, the smaller RMS values of the AQGQ models in Table 1 indicate that the inclusion of local gravity observations is a preferable modelling technique in areas of steep gravity gradients and low-lying topography.

\subsection{Quasigeoid (height anomaly) comparisons}

Figure 5 (top) presents the height anomalies along the traverse for all three quasigeoid models and the new VD dataset. At the starting point $(0 \mathrm{~km})$, all height anomalies were set to zero. Towards the end of the traverse, the height anomaly differences reach $\sim 2.7 \mathrm{~m}$, equating to a gradient of $71 \mathrm{ppm}$. The differences in the quasigeoid heights are shown in Fig. 5 (bottom). The RMS differences between the observed and modelled height anomalies remain at the \pm 20 -30 mm-level (Table 2). The AGQG2017 differences reach their maximum value at the eastern end of the traverse, while the AGQG2009 and GGMplus reach their maximum, of up to $\sim 50 \mathrm{~mm}$, between $25 \mathrm{~km}$ and $30 \mathrm{~km}$ along the traverse. Up to $15 \mathrm{~km}$, the differences among the quasigeoid heights show little variation, but exhibit a steady decrease. This is a direct translation of any biases in the $\eta$-differences into the quasigeoid domain, which causes a trend in the quasigeoid height differences.

From $15 \mathrm{~km}$ onwards, the curves start to diverge. From this point on, the GGMplus differences show a wave-like signal (10-20 mm amplitude), likely reflecting the impact of unmodelled bulk density across the Darling Fault. In contrast, the AGQG2017 curve is largely dominated by a trend and only shows shortscale variations. Consequently, the VD traverse experiment suggests AGQG2017 maps the quasigeoid's fine structure properly, but contains a tilt of $1-2 \mathrm{~mm}$ over $1 \mathrm{~km}$ (1-2 ppm) in the Perth region. This tilt translates into a bias of $\sim 0.2$ " in the $\eta$-component. 

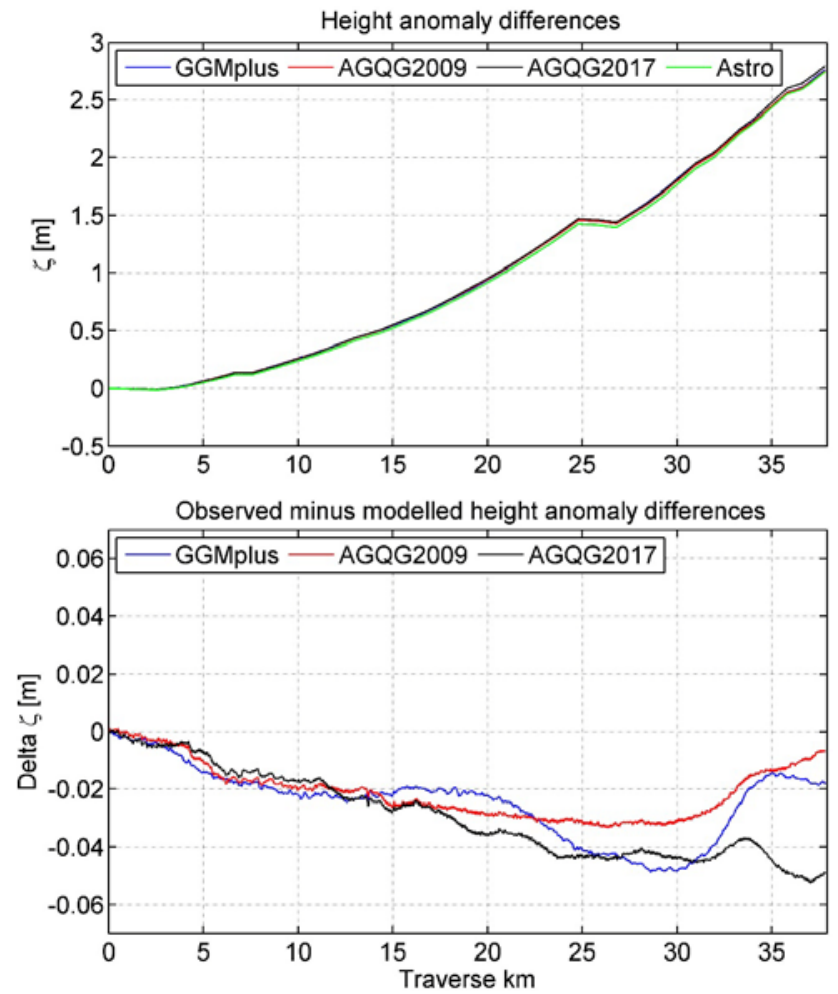

Fig. 5. Top: height anomaly differences (in metres) along the Perth traverse from GGMPlus (blue), AGQG2009 (red), AGQG2017 (black) and VD survey (green). Bottom: Differences between height anomalies (in metres) from the astronomicaltopographical solution and from the models (GGMplus, AGQG2009 and AGQG2017). The height anomaly of each solution or model was set to zero at the beginning of the traverse.

Table 2. Descriptive statistics of the quasigeoid height differences along the traverse. Units in $\mathrm{mm}$.

\begin{tabular}{ccccc}
\hline \multicolumn{1}{c}{$\Delta \boldsymbol{\zeta}$} & Min & Max & Mean & RMS \\
\hline Observed-GGMplus & -49 & 0 & -24 & \pm 27 \\
Observed-AGQG2009 & -33 & 1 & -21 & \pm 23 \\
Observed-AGQG2017 & -52 & 1 & -29 & \pm 33 \\
\hline
\end{tabular}

Over the Darling Fault ( $\sim 33 \mathrm{~km}$ along the profile), the gravity field models are not able to capture the geoid variations as consistently as in the western part, which is indicated by the larger discrepancies and the higher variability in the $\eta$-differences from $\sim 20 \mathrm{~km}$ to $\sim 35 \mathrm{~km}$ (cf. Fig. 4). This may be attributed to the fact that GGMplus employs a constant topographic mass density in the forward modelling at spatial scales of less than $\sim 10 \mathrm{~km}$, which prohibits a detailed description of the high-frequency gravitational signature of the mass-density variations associated with the Darling Fault.

With formally propagated AGQG2017 gravimetric quasigeoid errors (Featherstone et al. 2017) ranging between $\pm 83 \mathrm{~mm}$ and $\pm 98 \mathrm{~mm}$ along the traverse, the differences in Fig. 5 (bottom) are within the expected error budgets.

\subsection{Discussion}

A plausible explanation for the tilts in the quasigeoid models is that the traverse is in a coastal area, where marine gravity field information derived from satellite altimetry data is less reliable (e.g., Vignudelli et al. 2011). If the altimetry data are incorrect, the introduction of a tilt in the quasigeoid of some 0.1 " is entirely possible. Figure 6 shows a subset of the point gravity anomaly errors used in AGQG2017, comprising formally propagated errors for land gravity observations and the error grids that accompany the Sandwell et al. (2014) marine gravity anomalies.

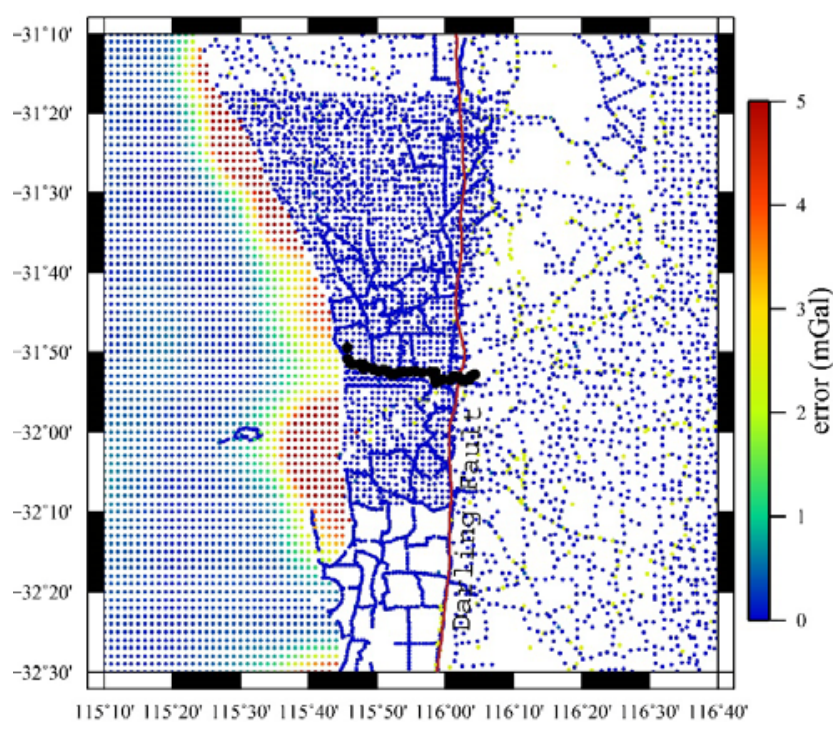

Fig. 6. Gravity anomaly errors used in AGQG2017. Units in $\mathrm{mGal}$. Rectangular projection.

From Fig. 6, the advantage of the astronomical method becomes clear: While only local data along the traverse is needed to compute the astronomical solution, the numerical integration in two coordinate directions requires gravity data outside our study area. The degradation of the marine gravity data is the prime suspect for the tilts in the quasigeoid models, adding yet more evidence that airborne gravimetry should be used to bridge this deficiency (e.g., Schwarz and $\mathrm{Li}$ 1996, Li et al. 2016, Jamil et al. 2017). AGQG2017 uses an integration cap of $55 \mathrm{~km}$, so the extents of Fig. 6 correspond to the local gravity data errors used in its computation.

An unintended outcome of this study is that the QDaedalus instrument was proven capable of mapping the horizontal location of the Darling Fault. The Fault is obscured by weathered regolith that prevents accurate mapping from surface geology observations. The inflections in $\eta$ at $33 \mathrm{~km}$ (Fig. 4) indicate that this is the location of the near-vertical fault line. However, this is a dramatic density contrast, so 
QDaedalus may not be able to map other less prominent faults.

\section{Summary and concluding remarks}

This study has presented results from the first digital VD measurements in the Southern Hemisphere. The observations were carried out in Perth with contemporary astrogeodetic QDaedalus instrumentation at the $\sim \pm 0.2$ " accuracy level. The comparison between the newly measured and modelled VDs showed an RMS agreement between $\sim \pm 0.5$ " and $\sim \pm 0.9$ " for $\eta$ and better than $\sim \pm 0.3$ " for $\xi$, which is commensurate with results from Northern Hemisphere countries (e.g., Wang et al. 2017; Hirt et al. 2010a).

Tilt-like biases of $\sim 1 \mathrm{~mm}$ over $1 \mathrm{~km}(1 \mathrm{ppm})$ are present for all quasigeoid models within $\sim 20 \mathrm{~km}$ of the coastline, which might either point at inconsistencies in the model-underlying coastal zone gravity data sets (e.g., offsets in the transition between altimeter and land gravity data), or remaining systematic errors in the VD observations. The latter explanation is considered less likely because the instrumentation did not show such systematic behaviour against control data (Hauk et al. 2017) and repeat observations (Sect. 2).

For our measurement campaign, the logistical requirements were comparatively low. The measurement equipment was transported by commercial commuter aircraft and moved between stations with a small car. Our VD campaign was designed as a lowcost project (less than AU $\$ 10,000$ ), potentially allowing its replication in other countries (e.g., Asia, Africa or South America) or even Antarctica to improve the global VD data coverage and rectify the current geographical VD imbalance between Northern and Southern Hemispheres. In turn, this will allow for improved global testing of high-degree gravity field models (such as the anticipated EGM2020).

As next steps, the new VDs collected in this study shall be used for testing of future gravity field models and modelling techniques in the Perth Basin, also with a focus on geophysical modelling of the fault. GPS/levelling data as another independent source for quasigeoid information should be collected along the traverse. An airborne gravity campaign, which would be desirable to improve the coastal gravity situation, is currently not planned.

\section{Data statement}

The authors see the project as the beginning of a long-term effort towards a global geodetic VD data base for gravity field validation. This VD data set is freely available via https://mediatum.ub.tum.de/1399846 to interested researchers.

\section{Acknowledgements}

We would like to thank: 1) DAAD (German Academic Exchange Service) and Universities Australia for funding this project, 2) Jo Jensen of C. R. Kennedy, Perth, for providing a back-up total station, 3) DFG (German Research Foundation) grant Hi1760/1, and 4) Scripps Institution of Oceanography (University of California), the US National Oceanographic and Atmospheric Administration and the National Geospatial-Intelligence Agency for permission to use the marine gravity anomalies from Sandwell et al. (2014).

\section{References}

Bosch W, Wolf H (1974) Über die Wirkung von topographischen Lokal-Effekten bei profilweisen Lotabweichungs-

Prädiktionen. Mitteilungen aus dem Institut für Theoretische Geodäsie der Universität Bonn Nr. 28

Brown CG, Sarabandi K, Pierce LE (2005) Validation of the Shuttle Radar Topography Mission height data, IEEE Transactions on Geoscience and Remote Sensing 43(8) 1707-1715, doi: 10.1109/TGRS.2005.851789

Bürki B (1989) Integrale Schwerefeldbestimmung in der IvreaZone und deren geophysikalische Interpretation. Geodätischgeophysikalische Arbeiten in der Schweiz, Nr. 40, Schweizerische Geodätische Kommission

Davidson WA (1995) Hydrogeology and groundwater resources of the Perth region, Western Australia. PhD thesis: Curtin University of Technology, School of Applied Geology

Featherstone, W.E. (1995) On the use of Australian geodetic datums in gravity field determination. Geomatics Research Australasia 62: 17-36

Featherstone WE, Rüeger JM (2000) The importance of using deviations of the vertical in the reduction of terrestrial survey data to a geocentric datum. The Trans-Tasman Surveyor 1(3): 46-61. doi: 10.1080/00050326.2000.10440341 [Erratum in The Australian Surveyor 47(1): 7] doi: 10.1080/00050356.2002.10558836

Featherstone WE, Lichti DD (2009) Fitting gravimetric geoid models to vertical deflections. Journal of Geodesy 83(6): 583-589. doi: 10.1007/s00190-008-0263-4

Featherstone WE, Kirby JF, Hirt C, Filmer MS, Claessens SJ, Brown NJ, Hu G, Johnston GM (2011) The AUSGeoid09 model of the Australian Height Datum. Journal of Geodesy 85(3): 133-150. doi: 10.1007/s00190-010-0422-2

Featherstone WE, McCubbine JC, Brown NJ, Claessens SJ, Filmer MS, Kirby JF (2017) The first Australian gravimetric quasigeoid model with location-specific uncertainty estimates. Journal of Geodesy. doi: 10.1007/s00190-017-1053-7

Forsberg R (1984) A study of terrain reductions, density anomalies and geophysical inversion methods in gravity field modelling. Report 355, Department of Geodetic Science and Surveying, Ohio State University, Columbus, USA

Fischer I, Slutsky M, Shirley FR, Wyatt III PY (1968) New pieces in the picture puzzle of an astrogeodetic geoid map of the world. Bulletin Géodésique 88(1): 199-221. doi: 10.1007/BF02525661

Fryer JG (1972) The Australian Geoid, The Australian Surveyor 24(4): 203-214. doi: 10.1080/00050326.1972.10440630

Guillaume S (2015) Determination of a Precise Gravity Field for the CLIC Feasibility Studies. Dissertation Nr. 22590, Eidgenössische Technische Hochschule ETH Zürich, Switzerland. doi: 10.3929/ethz-a-010549038

Guillaume S, Bürki B, Griffet S, Mainaud-Durand H (2012) QDaedalus: Augmentation of total stations by CCD sensor for automated contactless high-precision metrology. FIG 
Proceedings 2012,

https://www.fig.net/resources/proceedings/fig_proceedings/fi g2012/papers/ts09i/TS09I_guillaume_buerki_et_al_6002.pdf

Hauk M, Hirt C, Ackermann C (2017) Experiences with the QDaedalus system for astrogeodetic determination of deflections of the vertical. Survey Review 49(355): 294-301. doi: 10.1080/00396265.2016.1171960

Heiskanen WA, Moritz H (1967) Physical geodesy. W.H. Freeman, San Francisco

Helmert FR (1880/1884) Die mathematischen und physikalischen Theorien der höheren Geodäsie. Teubner, Leibzig (reprint Minerva, Frankfurt a.M. 1961)

Hirt C (2006) Monitoring and analysis of anomalous refraction using a digital zenith camera system. Astronomy and Astrophysics 459 (1): pp. 283-290. doi: 10.1051/00046361:20065485

Hirt C, Denker H, Flury J, Lindau A, Seeber G (2007) Astrogeodetic validation of gravimetric quasigeoid models in the German Alps - first results. Proc. First Int. Symp. of the International Gravity Field Service, Istanbul, Turkey, 28. Aug.01. Sept. 2006, Harita Dergisi, 18, 84-89, Ankara

Hirt C, Seeber G (2007) High-resolution local gravity field determination at the sub-millimeter level using a digital zenith camera system. In: Proc., Dynamic Planet, Cairns 2005 (ed. P. Tregoning und C. Rizos), IAG Symposia 130, 316-321

Hirt C, Feldmann-Westendorff U, Denker H, Flury J, Jahn C-H, Lindau A, Seeber G, Voigt C (2008) Hochpräzise Bestimmung eines astrogeodätischen Quasigeoidprofils im Harz für die Validierung des Quasigeoidmodells GCG05. Zeitschrift für Vermessungswesen 133: 108-119

Hirt C, Flury J (2008) Astronomical-topographic levelling using high-precision astrogeodetic vertical deflections and digital terrain model data. Journal of Geodesy 82(4-5): 231-248. doi: 10.1007/s00190-007-0173

Hirt C, Seeber G (2008) Accuracy Analysis of vertical deflection data observed with the Hannover Digital Zenith Camera System TZK2-D. Journal of Geodesy 82(6): 347-356. doi: 10.1007/s00190-007-0184-7

Hirt C, Bürki B., Somieski A, Seeber G (2010a) Modern determination of vertical deflections using digital zenith cameras. Journal of Surveying Engineering 136(1): 1-12. doi: 10.1061/ASCE_SU.1943-5428.0000009

Hirt C, Marti U, Bürki B, Featherstone WE (2010b) Assessment of EGM2008 in Europe using accurate astrogeodetic vertical deflections and omission error estimates from SRTM/DTM2006.0 residual terrain model data. Journal Geophysical Research - Solid Earth 115(B10), B10404. doi: 10.1029/2009JB007057

Hirt C, Schmitz M, Feldmann-Westendorff U, Wübbena G, Jahn C-H, Seeber G (2011) Mutual validation of GNSS height measurements from high-precision geometric-astronomical levelling. GPS Solutions 15(2): 149-159. doi 10.1007/s10291-010-0179-3

Hirt C, Claessens SJ, Fecher T, Kuhn M, Pail R, Rexer M (2013) New ultra-high resolution picture of Earth's gravity field. Geophysical Research Letters 40(16): 4279-4283. doi: 10.1002/grl.50838

Jamil H, Kadir, M, Forsberg R, Olesen A, Isa MN, Rasidi, S, Mohamed A, Chihat Z, Nielsen E, Majid F, Talib K, (2017) Airborne geoid mapping of land and sea areas of East Malaysia. Journal of Geodetic Science 7(1): 84-93. doi: 10.1515/jogs-2017-0010.

Jekeli C (1999) An analysis of vertical deflections derived from high-degree spherical harmonic models. Journal of Geodesy 73(1): 10-22. doi: 10.1007/s001900050213
Kotsakis, C. (2009), A study on the reference frame consistency in recent Earth gravitational models. Journal of Geodesy 83:31. https://doi.org/10.1007/s00190-008-0227-8

Li X, Crowley JW, Holmes SA, Wang YM (2016) The contribution of the GRAV-D airborne gravity to geoid determination in the Great Lakes region. Geophysical Research Letters 43(9), pp.4358-4365. doi: 10.1002/2016GL068374

Marti U (1997), Geoid der Schweiz 1997. Geodätischgeophysikalische Arbeiten in der Schweiz Nr. 56, Schweizerische Geodätische Kommission

Middleton MF, Wilde SA, Evans BA, Long A and Dentith MC (1993) A preliminary interpretation of deep seismic reflection and other geophysical data from the Darling Fault zone, Western Australia. Exploration Geophysics 24(3-4), 711718. doi: 10.1071/EG993711

Moritz H (2000) Geodetic Reference System 1980. Journal of Geodesy 74(1): 128-140. doi: 10.1007/s001900050278

Pavlis NK, Holmes SA, Kenyon SC, Factor JK (2012) The development and evaluation of the Earth Gravitational Model 2008 (EGM2008). Journal of Geophysical Research - Solid Earth, 117(B4), B04406. doi: 10.1029/2011JB008916

Pavlis NK, Holmes SA, Kenyon SC, Factor JK (2013) Correction to "The development and evaluation of the Earth Gravitational Model 2008 (EGM2008)”. Journal of Geophysical Research - Solid Earth, 118(B5), 2633. doi: 10.1002/jgrb.50167

Sandwell DT, Müller RD, Smith WHF, Garcia E, Francis R (2014) New global marine gravity model from CryoSat-2 and Jason-1 reveals buried tectonic structure. Science 346(6205): 65-67. doi: 10.1126/science.1258213

Schwarz KP, Li YC (1996) What can airborne gravimetry contribute to geoid determination? Journal of Geophysical Research - Solid Earth 101(8):17873-17881. doi: 10.1029/96JB00819

Smith DA, Holmes SA, Li X, Guillaume S, Wang YM, Bürki B, Roman DR, Damiani TM (2013) Confirming regional $1 \mathrm{~cm}$ differential geoid accuracy from airborne gravimetry: The geoid slope validation survey of 2011. Journal of Geodesy 87(10-12): 885-907. doi: 10.1007/s00190-013-0653-0

Torge W, Müller J (2012) Geodesy. 4th Edition, De Gruyter, Berlin/Boston

Vignudelli S, Kostianoy A, Cipollini P, Benveniste J (eds) (2011) Coastal altimetry. Springer, Berlin, 566pp. doi: 10.1007/9783-642-12796-0

Voigt C (2013) Astrogeodätische Lotabweichungen zur Validierung von Schwerefeldmodellen. Deutsche Geodätische Kommission C 702, München

Voigt C, Denker H, and Hirt C (2009). Regional astrogeodetic validation of GPS/levelling data and quasigeoid models. in: Sideris, M. G. (ed.) Observing Our Changing Earth, Springer, Berlin, pp 413-420

Voigt C, Denker H (2013) Validation of second generation GOCE gravity field models by astrogeodetic vertical deflections. IAG Proceedings 139, 291-296. doi: 10.1007/978-3642-37222-3_38

Wang, Y M, Becker C, Mader G, Martin D, Li X, Jiang T, Breidenbach S, Geoghegan C, Winester D, Guillaume S, Bürki B (2017) The Geoid Slope Validation Survey 2014 and GRAV$\mathrm{D}$ airborne gravity enhanced geoid comparison results in Iowa. Journal of Geodesy. doi: 10.1007/s00190-017-1022-1

Watts AB (2001) Isostasy and Flexure of the Lithosphere. Cambridge University Press, Cambridge 